\title{
XI.
}

\section{Ueber den Bau und das Aufsaugungsvermögen des Peritonäum.}

\author{
Anatomische und experimentelle Untersuchungen.
}

(Aus dem Institut für allgemeine Pathologie an der Universität Turin.)

Von Dr. G. Muscatello ${ }^{1}$ ).

(Hierzu Taf. VII.)

I. An welchen Stellen des Peritonäum findet unter normalen Verhältnissen die Aufsaugung statt?

Vor mehr als 30 Jahren gelang es. v. Recklinghausen (1862), durch Thierversuche und mikroskopische Untersuchungen am $\mathrm{Zwerchfell} \mathrm{festzustellen,} \mathrm{dass} \mathrm{verschiedene} \mathrm{feinkörnige} \mathrm{Stoffe}$ (Milch, Zinnober, Chinesische Tusche, Oel, Blut, Eidotter) nach ihrer Einführung in die Bauchhöhle durch das Centrum tendineum des Zwerchfells hindurch in das Lymphgefässsystem aufgenommen werden und einige Zeit später in den mediastinalen Lymphdrüsen und im Ductus thoracicus erscheinen. Diese Beobachtung wurde bald darauf durch die Arbeit von Ludwig und Sch weiggerSeidel (1866) im Wesentlichen bestätigt. Auspitz (1871) konnte in seinen Versuchen am Kaninchen nicht nur beobachten, dass das in die Bauchhöhle des Thieres eingeführte Reismehl durch das Zwerchfell aufgesogen wurde, sondern stellte auch fest, dass die Körnchen nach 1 Stunde im Blute der Ohrmuschel in grosser Menge auftreten und einige Stunden später in der Lunge, Leber, Milz und Nieren abgelagert werden. Beck (1893) giebt in einer neueren Arbeit an, dass die ersten Körnchen im Lymphstrom des Iuctus thoracicus 1-2 Stunden nach Einführung derselben in die Bauchhöhle erscheinen.

Durch diese Beobachtungen war demnach erwiesen, dass dem Theil des Peritonäum, welches dem Centrum tendineum des

1) Deutsche Uebersetzung von Dr. Otto Roether in Offenbach a. M. 

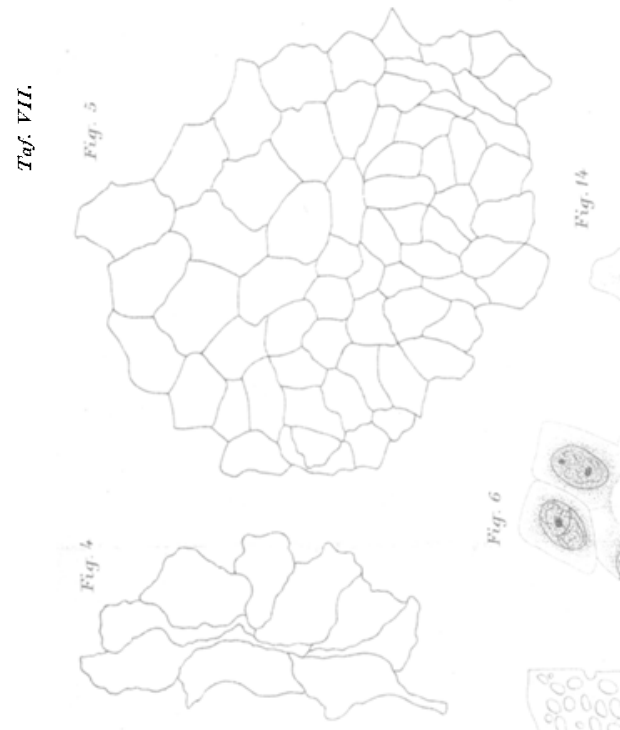

i

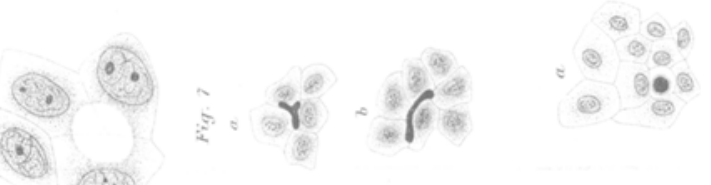
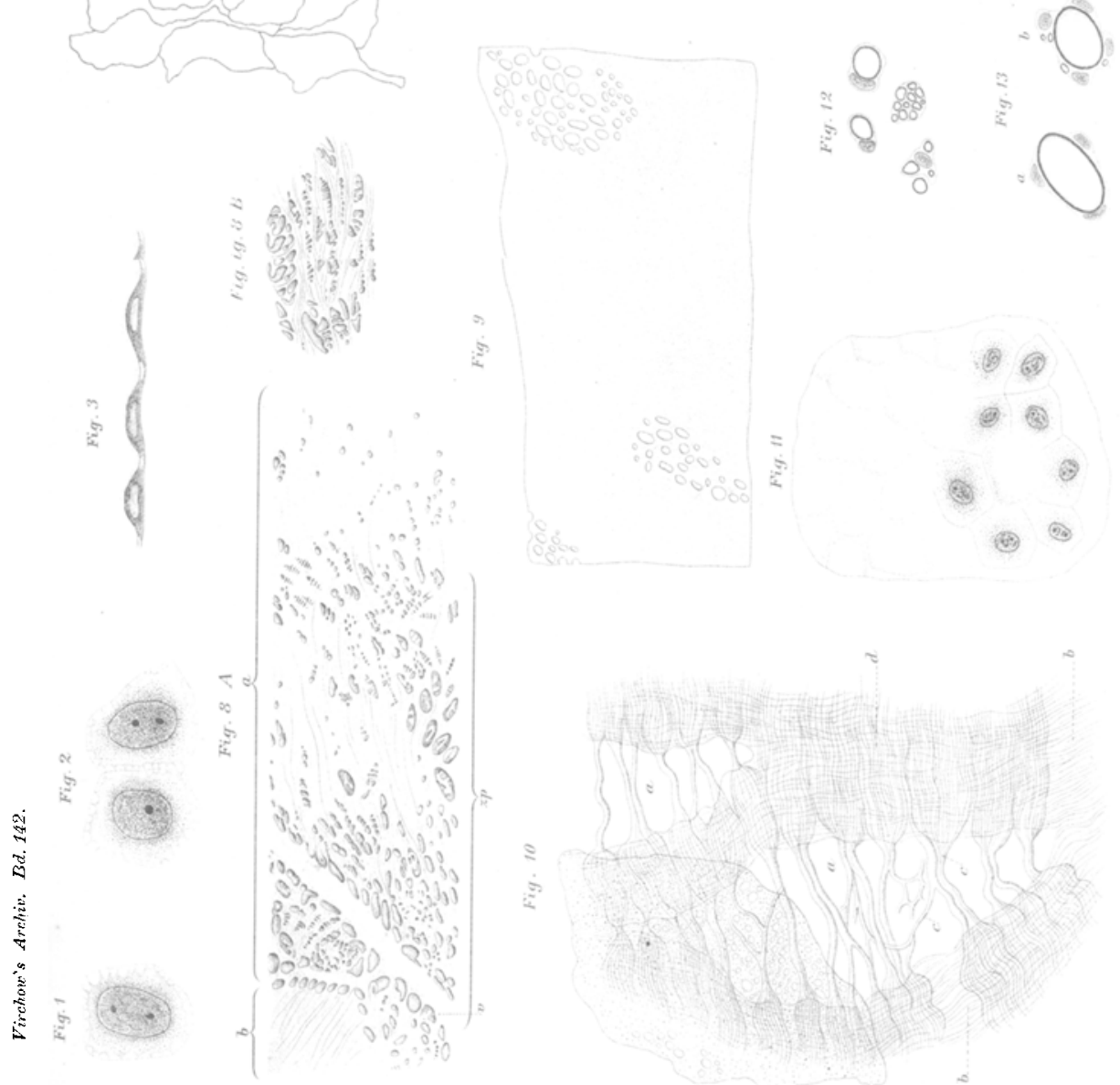

(18) 61

(9) 8

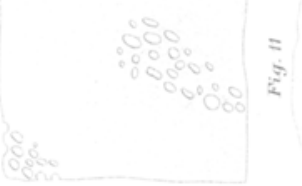

(8) 8

(6) 20

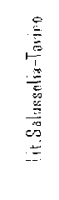

..

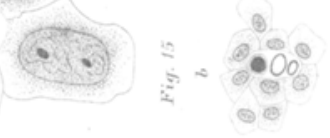

$+$

(3) 
Zwerchfells entspricht, ein gewisses Aufsaugungsvermögen für verschiedene fremde Körper zukommt, und dass die aufgenommenen Körnchen später in den verschiedenen Organen abgelagert werden.

Andere Arbeiten beschäftigen sich mit der Frage, ob ausser

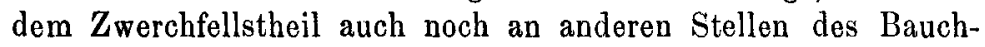
fells ein Uebertritt fremder Körper in die Lymphbahnen stattfindet. Dubar und Remy (1882) waren die ersten, welche sich für das Vorhandensein noch anderer Absorptionsstellen aussprachen. Sie behaupteten, dass die Aufsaugung von feinkörnigen, in die Peritonäalhöhle eingeführten Stoffen "sowohl auf dem Lymph-, wie auf dem Blutwege statthaben kann, dass sie in dem ersten Fall ausschliesslich durch das $Z$ werchfell hindurch, in dem zweiten durch die Pfortaderwurzeln vor sich geht". Ein vollgültiger Beweis für diese letztere Behauptung, welcher bei der Wichtigkeit des Gegenstandes unerlässlich war, wird allerdings in der Arbeit vermisst.

Die Zahl der absorbirenden Stellen wurde in der Folge durch die Forschungen von Maffucci (1882) noch vermehrt. Auf Grund ausgedehnter experimenteller Untersuchungen kam er zu dem Ergebniss, dass "ausser dem Zwerchfell auch das Netz, das Ligamentum latum, das Ligamentum gastro-hepaticum und gastro-splenicum, die Douglas'schen Falten, das Mesorectum und ausnahmsweise auch das Mesenterium, Wege für die Aufnahme feinkörniger Stoffe enthalten“. Diese Schlussfolgerungen stützen sich auf Versuche, in welchen Aufschwemmungen Chinesischer Tusche in die Bauchhöhle von Hunden eingebracht und darauf nach 1-6-24-90 Stunden die thoracalen und abdominalen Lymphdrüsen, die Leber, die Milz und verschiedene Stellen der Serosa selbst untersucht worden waren. Schon jetzt wollen wir bemerken, dass Maffucci hauptsächlich die Ergebnisse der nach 6 Stunden und darüber vorgenommenen Untersuchungen für seine Schlüsse berücksichtigt hat, während er die in der ersten Stunde gefundenen Resultate nur kurz erwähnt, ein Umstand, dessen Bedentung wir bald kennen lernen werden.

Bei meinen eigenen, in der Absicht einer Nachprüfung der bisherigen Forschungsergebnisse angestellten Untersuchungen beputzte ich in der ersten Versuchsreihe theils Kaninchen, theils, 
und zwar mit Vorliebe, Hunde. Da der Hund nach Ellenberger ein verhältnissmässig gering entwickeltes Lymphgefässsystem besitzt, kann sich die Untersuchung auf eine ziemlich kleine Anzahl von Lymphdrüsen beschränken, wodurch der Nachweis der Wege, auf denen sich die Körnchen im Körper verbreiten, bedeutend erleichtert wird. Von körnigen Substanzen benutzte ich nach verschiedenen Vorversuchen Chinesische Tusche und mehr noch Carmin; letzterem gab ich deshalb den Vorzug, weil bei der Tusche Verwechselungen mit den feinen schwarzen Pigmentkörnchen möglich sind, welche normalerweise in den Lymphdrüsen, der Milz, der Leber und anderen Organen vorkommen.

Durch eine in der Linea alba unterhalb des Nabels eingeführte Canüle wurde die mit physiologischer Kochsalzlösung angefertigte, auf $37^{\circ}$ erwärmte Körnchenaufschwemmung in die Bauchhöhle des Thieres eingespritzt. Die Menge der Flüssigkeit war so bemessen, dass $15 \mathrm{ccm}$ derselben auf $1 \mathrm{~kg}$ Thier entfielen. In einigen Versuchen, die dem Studium der Aufnahme von rothen Blutkörperchen dienen sollten, wurde dem Versuchsthier defibrinirtes, mit Kochsalalösung verdünntes Blut derselben Thiergattung in die Peritonäalhöhle eingebracht.

Schon bei den ersten Versuchen machte ich die Beobachtung, dass die sehr feinkörnigen Stoffe das Diaphragma mit grösster Schnelligkeit durchdringen und sich schon 5-7 Minuten nach der Einführung in die Bauchhöhle in den retrosternalen und mediastinalen Lymphdrüsen vorfinden. Dieser Befund wiederholte sich mir so beständig, dass die Nichterwähnung desselben durch die früheren Beobachter - mit alleiniger Ausnahme von Dubar und Remy - sehr auffällig erscheint.

Des Weiteren konnte ich durch mannichfaltige Abänderung der Versuchsbedingungen feststellen, dass die Durchtrittsgeschwindigkeit der Körnchen noch erhöht wird, wenn man das Thier während des Versuchs mit gesenktem Oberkörper in etwas schräger Lage hält; offenbar wird unter diesen Bedingungen die Aufnahme der Körnchen in die Lymphspalten des Zwerchfells sowohl durch ihre eigene Schwere, als auch durch den Druck der eingeführten Flüssigkeitssäule begünstigt.

Wenden wir uns jetzt zur näheren Betrachtung der Wege, durch welche die Aufsaugung stattfindet. 
Bei einem, wenige Minuten nach Einführung von Carmin gotödteten Hunde lässt sich durch genaue makroskopische und mikroskopische Untersuchung der Organe regelmässig folgender Befund feststellen: Noch ehe die bekannte (von v. Recklinghausen, Ludwig, Bizzozero so schön beschriebene) Anfüllung des diaphragmatischen Lymphgefässnetzes für das blosse Auge wahrnehmbar ist, enthalten sowohl die hinter dem Brustbein, wie die im vorderen und hinteren Mediastinum gelegenen Lymphdrüsen Carminkörnchen, während sich in den Lymphdrüsen der Bauchböhle und in den inneren Organen noch keine Spur derselben vorfindet.

Durchaus abweichend gestaltet sich der Befund bei einem 6 Stunden nach Einführung von Carmin getödteten Hunde. Jas Lymphgefässnetz des Zwwerchfells bietet eine prächtige Carmininjection, die besonders auf der pleuralen Seite ausgeprägt ist. Die im Centrum tendineum und in der Zona peritendinea engen Maschen dieses Netzes werden nach der Peripherie hin immer weiter, und gehen endlich in vier grosse Lymphgefässstämme über, von denen zwei ventralwärts als retrosternale Stämme dem Verlauf der Venae mammariae internae folgen, zwei dorsalwärts nach dem hinteren Mediastinum verlaufen. Auch hier findet sich das Carmin in den mediastinalen und retrosternalen Lymphdrüsen abgelagert; viel wichtiger ist jedoch der Befund derselben Körnchen in den Lymphdrüsen der Bauchhöhle, von denen die Drüsen am Hilus der Leber und der Milz eine grössere, die an der grossen Curvatur des Magens in der Pylorusgegend gelegene grosse Lymphdrüse, das sogenannte Pankreas Aselli, die lumbaren und präaortischen Drüsen eine kleinere Menge enthalten; in den Mesenterialdrüsen endlich ist die Menge der Carminkörnchen so gering, dass sie für das blosse Auge oft ganz frei davon erscheinen, während man bei mikroskopischer Durchmusterung der Schnitte gewöhnlich eine Anzahl derselben entdeckt. Die Leber enthält zahlreiche Körnchen, sowohl in den Capillaren der Acini, als auch in den Interlobulärräumen rings um die Gefässe, und zwar sind die Körnchen theils frei, theils in Wanderzellen eingeschlossen. Auch in den Lymphräumen der Milz finden sich die Körnchen sowohl frei, wie als Einschluss von Leukocyten. 
In geringerer Anzahl können die Körnchen noch in anderen parenchymatösen Organen, in der Lunge, im Pankreas und im Hoden nachgewiesen werden; in der Lunge liegen sie theils in den Capillaren, theils in den subpleuralen und perivasculären Iymphräumen; in der Bauchspeicheldrüse und im Hoden finden sie sich sehr spärlich, in farblose Zellen eingeschlossen, in der Umgebung der Blutgefässe.

Der beschriebene Befund deckt sich im Wesentlichen mit den Ergebnissen, welche Maffucci in seinen Versuchen von gleicher Zeitdauer (6 Stunden) erhalten hat; ein Unterschied liegt nur darin, dass dieser Forscher von den parenchymatösen Organen nur die Leber und die Milz als Sitz der Körnchen erwähnt, ferner darin, dass er in den Mesenterialdrüsen von den eingeführten Körnchen nichts nachweisen konnte.

Nach einem noch längeren Zeitraum endlich (16 Stunden) findet man die Carminkörnchen ausser in den oben genannten Organen auch in den axillaren und poplitealen Lymphdrüsen.

Die eben ausgeführten Versuchsergebnisse lassen sich in folgenden zwei Sätzen kurz zusammenfassen: 1) wenige Minuten nach der Einführung in die Bauchhöhle finden sich die Körnchen ausschliesslich in den intrathoracischen Lymphdrüsen; 2) nach 6 Stunden und später trifft man sie auch in den abdominalen Lymphdrüsen und in den parenchymatösen Organen.

Diese Thatsachen sucht Maffucci durch die Annahme za erklären, dass ausser am $Z$ werchfell noch an anderen Stellen des Peritonäum gewissermaassen "untergeordnete" Wege für die Aufsaugung vorhanden seien.

So wahrscheinlich diese Erklärung von Maffucci auch klingen mag, so giebt sie doch zu einigen Ueberlegungen Anlass.

1. Es ist richtig, dass das verspätete Auftreten von Körnchen in den abdominalen Lymphdrüsen sich durch ein geringeres Aufsaugungsvermögen der "untergeordneten Absorptionsstellen" erklären lässt, aber ebenso sicher ist es auch, dass die Körnchen in diesen Fällen schon seit Stunden nicht nur in das Lymphgefässsystem (in die thoracischen Drüsen, wie unsere Versuche lehren, bereits nach 5 Minuten), sondern sogar in die Blutgefässe übergegangen waren; wurden ja doch in den Versuchen von Auspitz und von Beck die in die Bauchhöhle eingespritzten 
Körnchen schon nach $1-1 \frac{1}{2}$ Stunden in den Blutgefässen der Ohrmuschel, bezw. im Lymphstrom des Ductus thoracicus aufgefunden.

2. Die in den Blutkreislauf übergegangenen Körnchen werden sehr schnell in den inneren Organen, besonders in der Leber und in der Milz, abgelagert; Werigo hat das überzeugend durch Versuche dargethan, bei welchen er die in eine Ohrvene des Kaninchens eingespritzten Carminkörnchen schon nach 2-4 Minuten in der Leber und fast gleichzeitig in der Milz auftreten sah. Es fragt sich nun, bleiben die in diese Organe gelangten Körnchen daselbst liegen oder werden sie weiterhin durch die Blut- oder Lymphgefässe nach anderen Orten verschleppt?

3. Dass übrigens die Körnchen in unseren Versuchen die Leber auf der normalen Blutbahn erreicht haben, beweist ihre Vertheilung in dem Organ; so hebt auch Maffucci ganz richtig hervor, dass die Lage der Körnchen in der Leber dieselbe ist, einerlei ob die Aufschwemmung in die Bauchhöhle oder unmittelbar in die Vena jugularis eingebracht wurde.

Da es demnach feststeht, dass die Körnchen schon nach wenigen Stunden im Blute kreisen und in einigen parenchymatösen Organen abgelagert werden, so liegt doch der Einwand nahe genug, dass, wenn nicht alle, so doch ein Theil der nach 6 Stunden in den abdominalen Lymphdrüsen aufgefundenen Körnchen auf dem Lymphwege aus den parenchymatösen Organen nach jene Drüsen verschleppt sein können.

Mit anderen Worten, es warf sich mir schon nach meinen ersten Versuchen die Frage auf: erreichen die Körnchen die abdominalen Lymphdrüsen unmittelbar, durch Aufsaugung von den "secundären Absorptionsstellen" des Peritonäum aus, oder auf dem Umwege des Blutkreislaufs, nachdem sie durch das Diaphragma in den Lymphstrom and von da in das Körperblut gelangt sind?

Zur Beantwortung dieser Frage war es nöthig, möglichst genau den Zeitpunkt festzustellen, zu welchem die Körnchen in den parenchymatösen Organen, bezw. in den abdominalen Lymphdrüsen erscheinen. In dieser Absicht unternahm ich eine Reihe von Versuchen, in welchen die Hunde bezw. 20, 30,

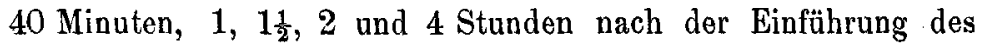


Carmins getödtet und dann die sämmtlichen Lymphdrüsen auf's Genaueste durchsucht wurden, während sich die Untersuchung der parenchymatösen Organe auf Leber und Milz beschränken konnte, weil in diesen erfahrungsgemäss am frühesten die Ablagerung der im Blute kreisenden Fremdkörper stattfindet.

Bei den Thieren, bei welchen der Versuch 20 Minuten bis 1 Stunde gedauert hat, bemerkt man lediglich eine fortschreitende Vermehrung der Körnchen in den thoracischen Lymphdrüsen, bis diese endlich ganz damit vollgestopft erscheinen. $Z u$ diesem Zeitpunkt finden sich die Körnchen weder in den Lymphdräsen der Bauchhöhle, noch in der Leber und in der Milz.

Erst nach $1 \frac{1}{2}$ Stunden treten in der Leber (in den Capillaren der Acini), und nach 2 Stunden auch in der Milz (in den venösen Räurnen) spärliche freie oder in Leukocyten eingeschlossene Körnchen auf.

Ebenfalls nach 2 Stunden begegnet man den ersten Körnchen in den Lymphdrüsen der Bauchhöhle, und zwar gerade in denjenigen, welche am Hilus der Leber und der Milz liegen, während alle übrigen noch ganz frei davon sind; erst in den darauf folgenden Stunden lassen sich die Körnchen auch in diesen nach weisen.

Ich darf an dieser Stelle wohl erwähnen, dass man mit der grössten Vorsicht zu Werke gehen muss, um zu vermeiden, dass die in der Bauchhöhle zerstreaten Körnchen beim Schneiden in die $z u$ untersuchenden Organe eindringen. $Z$ u diesem $Z$ weok nahm ich das ganze Organ aus dem Körper heraus, wusch es ausgiebig unter starkem Wasserstrahl und entnahm darauf mit einem ganz reinen Messer kleine Stückchen, welche nach der Härtung in Alkohol mit Hälfe des Mikrotoms geschnitten wurden.

Aus diesen Untersuchungen geht als feststehende Thatsache hervor, dass zu derselben Zeit, in welcher die ersten Körnchen in den abdominalen Lymphdrüsen auftreten, Leber und Milz die Körnchen schon enthalten. Es erübrigte jetzt noch zu untersuchen, ob dieses Zusammentreffen nicht ein rein zufälliges ist, da es ja immerhin denkbar wäre, dass die Körnchen etwa nach der Aufnahme durch das Netz oder durch das Ligamentum gastro-hepaticum u.s. w. zu 
derselben Zeit in die Lymphdrüsen gelangen, zu welcher andere Körnchen durch den Blutstrom der Leber zugetragen werden.

Um diesen $Z$ weifel zu beseitigen, war es nöthig, für eine gewisse Zeit das Absorptionsvermögen des Peritonaeum diaphragmaticum aufzuheben oder $\mathrm{zu}$ beschränken und die Körnchenaufschwemmung einzig und allein in Berührung mit dem Rest der Bauchfellserosa - genauer gesagt, mit einem grossen Theil derselben, unter Ausschluss des Zwerchfells, - zu lassen.

Da ich wusste, dass die Aufsaugung der Körnchen durch die Tieferlagerung des Brusttheils beschleunigt wird, versuchte ich das Absorptionsvermögen des Diaphragma dadurch zu beseitigen oder doch wenigstens einzuschränken, dass ich dem Thiere gerade die entgegengesetzte Stellung gab.

Einem in senkrechter Stellung, den Kopf nach oben, auf dem Brette festgebundenen Hunde wird die Carminaufschwemmung in die Bauchhöhle gebracht. Das Thier bleibt in dieser Stellang, so dass sich die Flüssigkeit in der caudalen Hälfte des Abdomen ansammelt und mit den Beckenorganen, dem grossen Netz und einem beträchtlichen Theil des Mesenterium iu Berührung steht.

Nach $1 \frac{1}{2}$ Stunden wird das Thier getödtet und die Organe genau untersucht; allein weder in den Lymphdrüsen der Brusthöhle, noch sonst in irgend einem Organ werden die Körnchen gefunden.

Nachdem mir dieser Versuch den Beweis geliefert hatte, dass die aufrechte Körperhaltung beim Hunde ungünstige Bedingungen für die Aufsaugung der Fremdkörper aus der Bauchhöhle schafft, benutzte ich diese Thatsache zu folgendem Versuch:

Ein starker Hund wurde in derselben Weise wie in dem vorhergehenden Versuch behandelt und nach $5 \frac{1}{2}$ Stunden getödtet. Bei der Untersuchung ergab sich, dass die intrathoracischen Lymphdrüsen Carminkörnchen enthielten, obwohl weder das Lymphgefässnetz des $Z$ werchfells noch die zwei retrosternalen Lymphstämme für das blosse Auge injicirt erschienen. - Alle abdominalen Drüsen dagegen (Drüsen der Pylorusgegend, des Milz- und Leberhilus, Pankreas Aselli, lumbare und präaortische Drüsen), sowie die Leber und die Milz waren frei von Körnchen.

Das Ergebniss dieses Versuches erscheint mir ausschlag- 
gebend für die Entscheidung unserer Frage. Wenn die Körnchen, welche wir bei den früheren Versuches in den abdominalen Lymphdrüsen gefunden haben, unmittelbar durch etwaige unterhalb des $Z_{\text {werchfells gelegene }}$ Absorptionsstellen eingedrungen wären, so hätten sie auch in diesem Versuch auf demselben Wege eindringen und sich in den Lymphdrüsen ablagern müssen.

Der negative Befund beweist dagegen zur Genüge, dass die Körnchen, welche in den Lymphdrüsen der Bauchhöhle angetroffen werden, zum grössten Theil auf dem Lymphwege aus den grossen parenchymatösen Organen dahin verschleppt sind, nachdem sie durch das $Z$ werchfell in den Lymphstrom aufgenommen waren und sich weiterhin durch die Blutbahn in den Organen verbreitet hatten. Zum kleineren Theil mögen übrigens die Körnchen diesen Drüsen auch durch ihre Vasa nutritia zugeführt sein. Es erklären sich jetzt auch einige Befunde, welche wir in den oben beschriebenen Versuchen feststellen konnten, sowie manche Ergebnisse aus den Experimenten anderer Forscher. So wird z. B. jetzt verständlich, weshalb gerade in den Lymphdrüsen am Hilus der Leber und der Milz die Körnchen zuerst und am frühesten in grösserer Menge auftreten, weil eben in denjenigen Organen, von welchen sie ihre Lymphe empfangen, die im Blute kreisenden Körnchen in erster Linie abgelagert werden. So erklärt sich auch die von Maffucci ganz richtig hervorgehobene Thatsache, dass die lumbaren Lymphdrüsen sehr zahlreiche Körnchen enthalten, da in ihnen die Lymphe von sämmtlichen Organen des kleinen Beckens zusammentrifft; ebenso erklärt sich der Reichthum an Körnchen in der am Pylorustheil der grossen Curvatur gelegenen Drüse daraus, dass sich hier wenigstens beim Hunde - die Lymphgefässe der grossen Curvatur des Magens fast ausschliesslich sammeln. Weshalb endlich die Mesenterialdrüsen so wenige Körnchen enthalten, dass sie manchmal ganz frei davon scheinen, ist einfach dadurch zu erklären, dass die Drüsen in sehr grosser Zahl vorhanden sind und jede von ihnen nur die Lymphe eines ganz kleinen Darmabschnittes erhält.

Ausserdem geht aber aus diesem letzten Versuche noch hervor, dass selbst unter den ungünstigsten Versuchsbedingungen die Aufsaugung, wenn auch viel langsamer als gewöhnlich, durch 
das Zwerchfell hindurch stattfindet, und diese Thatsache führt uns zu der Annahme, dass normalerweise in der Peritonäalhöhle nach dem $Z$ werchfell hin gerichtete Flüssigkeitsströmungen vorhanden sind.

Als Endergebniss der bis jetzt beschriebenen Versuche können wir demnach behaupten, dass unter gewöhnlichen Verhältnissen das $Z$ werchfell die einzige für die Aufsaugung bestimmte Stelleder Peritonäalserosa ist, und dass den Mediastinaldrüsen die Aufgabe zukommt, die aus der Bauchhöhle stammende Lymphe zu sammeln. So glaube ich den Gegenstand in geeigneter Weise aufgeklärt zu haben, weil man sich mit den von mir innegehaltenen Versuchsbedingungen den physiologischen Verhältnissen so viel wie möglich annähert, während das entgegengesetzte Verfahren, bei welchem die fremden Körper lange Zeit in Berührung mit der Serosa gelassen werden, nach meiner Ansicht für das Studium der normalen Absorptionsstellen keine brauchbaren Thatsachen zu liefern im Stande ist. Aus vielen Versuchen, bei welchen Fremdkörper in verschiedenster Absicht in die Bauchhöhle eingebracht wurden, ergiebt sich klar, dass die Serosa an der Stelle, an welcher sie von dem Fremdkörper berührt wird, Veränderungen eingeht, die je nach Gestalt, Grösse und Beschaffenheit seiner Oberfläche verschieden sind. Marchand, Roloff und Andere haben bewiesen, dass an der Berührungsstelle der Endothelüberzug zerstört wird; durch die ganze Dicke der Serosa, vornehmlich aber in ihren oberflächlichen Schichten, macht sich eine seröse Durchtränkung bemerklich, worauf Leukocyten in den Gowebsmaschen auftreten und eine feine Fibrinschicht um den Fremdkörper abgelagert wird. Diese Veränderungen sind, wio ich selbst in einigen zu anderem $Z_{\text {wecke angestellten Versuchen }}$ beobachten konnte, schon nach wenigen Stunden deatlich ausgesprochen.

Wenn wir nun die fremden Körnchen mit einer dermaassen veränderten Serosa längere Zeit in Berührung lassen, können wir da erwarten, äber physiologische Verhältnisse des Peritonäum Aufschluss zu erhalten? Bei den tiefgreifenden Störungen, welche sich nach einiger Zeit im Kreislauf und in der Ernährung der Serosa geltend machen, können die Körnchen, theils durch ihr 
Eigengewicht, theils durch Verschleppung von Seiten der zahlreichen in ihrer Umgebung auftretenden Leukocyten in die tieferen Schichten der Serosa eindringen und so leicht in die Lymphund Blutbahnen gelangen. Sehen wir dann unter solchen Umständen die Körnchen aus der Bauchhöhle in den Körper übergehen, so können wir höchstens die Möglichkeit zugeben, dass auch physiologischerweise ein solcher Uebergang stattfindet, aber eine bestimmte Schlussfolgerung in dieser Richtung wird durch eine solche Versuchsanordnung nicht ermöglicht.

Nach meiner Ansicht können die schönen Versuche von Maffucei über die Entwickelung und Verbreitung der Tuberculose im Peritonäum (Sulla patologia del peritoneo), obgleich sie eine Reihe von interessanten Aufschlüssen über diesen Gegenstand geliefert haben, in der Erörterung über die normalen Functionen der Bauchfellserosa nicht zar Entscheidung herangezogen werden. Dort handelt es sich um einen destruirenden chronisch-entzündlichen Vorgang, der, von einem Punkte der Serosa ausgehend, dieselbe fortschreitend von Grund aus verändert, bis schliesslich, wenn nicht gewisse, hier nicht zu erörternde Bedingungen im Wege stehen, die krankhaften Produkte in die Blut- und Lymphbahnen der Serosa eindringen, um an nähere oder entferntere Stellen verschleppt zu werden. Unter diesen Verhältnissen von einer Absorption durch das Peritonäum zu sprechen, scheint mir ebenso berechtigt, wie wenn man die metastatische Verbreitung eines ursprünglich auf der Haut oder Schleimhant sesshaften infectiösen Prozesses oder einer Neubildung als Absorptionsvorgang bezeichnen wollte.

Zum Schluss, dieses Capitels möchte ich noch einige Beobachtungen über die Lymphgefässe der Leber und die Einwanderung der Körnchen aus der Bauchhöhle in dieses Organ mittheilen.

Maffucci liess die Möglichkeit offen, dass die Körnchen ausser durch die Blutgefässe auch auf dem Lymphwege dem Blute zugetragen würden, und in seiner Arbeit „Ueber das Absorptionsvermögen des Peritonäum" stellte er die ganz neue Behauptung auf (für welche er in einer anderen Arbeit „Ueber die Pathologie des Peritonäum " 1883 weitere Beweise beizubringen suchte), dass die dem Verlauf der Pfortader folgenden lymph- 
gefässe des Leberhilus nicht, wie gewöhnlich angenommen wird, ausführende, sondern zufübrende Wege seien, auf denen Fremdkörper und pathologische Produkte aus der Bauchhöhle nach der Leber geschafft würden.

Durch folgenden Versuch konnte ich mich jedoch davon überzeugen, dass die Lymphgefässe an der Leberpforte in Wirkkeit abführende Wege darstellen.

Ein grosser Hund erhält 150-200 ccm einer auf.Körperwärme gebrachten 0,6 procentigen Kochsalzlösung in die Bauchhöhle. Nach 15-20 Minuten wird er mittelst Durchschneidung des Bulbus getödtet und die Bauchböble sofort geöffnet, in welcher nunmehr die stark gefüllten Lymphgefässe in ganzer Ausdebnung auf's Schönste zu überblicken sind. Auch die Gruppe von Lymphgefässen, welche den Wänden der Pfortaderäste aufliegen und mit diesen in die Leber eindringen, lässt sich bequem studiren und man sieht, dass diese Lymphbahnen in einer grossen, $3-5 \mathrm{~cm}$ rom Leberhilus gelegenen Lymphdrüse zusammentreffen. Um nun zu beweisen, dass dieselben wirklich ausführende Gefässe sind, genügt es, sie etwa in der Mitte ihres Verlaufes mit einem Glasstab zusammenzudrücken; man sieht dann ganz deutlich, wie der nach der Leber zu gelegene Theil stark anschwillt, während der nach der Lymphdrüse zu gelegene Theil sich mehr und mehr entleert; nach Aufbebung des Druckes erlangen die Gefässe sofort ibren früheren Umfang wieder. Diese Probe lässt sich mehrmals nach einander immer mit demselben Erfolg wiederholen.

Der stets gleich bleibende Erfolg dieses Versuches auch an anderen Hunden beweist mir, dass die Lymphgefässe am Leberhilus nach wie vor als Vasa efferentia angesehen werden müssen, eine Annahme, die übrigens durch die neuesten anatomischen Untersuchungen von Disse (1892) gestützt wird.

Demnach muss es als feststehend gelten, dass die Körnchen, welche nach der Einspritzung in die Bauchhöhle in der Leber auftreten, auf der Blutbahn in dieses Organ gelangt sind.

\section{Ueber den Bau der Bauchfollserosa.}

Nachdem ich mich durch die im vorigen Abschnitt wiedergegebenen Versuche davon überzeugt hatte, dass den einzelnen Theilen des Bauchfells ganz verschiedene Fähigkeiten zukommen, nahm ich mir vor zu untersuchen, ob dieser verschiedenen Function auch bestimmte Unterschiede im Bau der Serosa entsprechen. Ich hielt es von Vortheil, bei diesen Untersuchungen hauptsächlich das menschliche Peritonäum zu berücksichtigen, doch sind 
auch verschiedene Thiergattungen zur Vervollständigung der Ergebnisse herangezogen worden.

Als Ausgang diente mir die Arbeit von Bizzozero und G. Salvioli (1876) "Ueber den Bau des Peritonaeum diaphragmaticum des Menschen", durch welche verschiedene werthvolle Einzelheiten über den Bau der Serosa gewonnen worden sind. Durch diese Untersuchungen ist festgestellt, dass unter dem Endothel eine äusserst feine Membrana limitans gelegen ist, unter dieser eine ebenso dünne Schicht Bindegewebe, welche von den Forschern Stützgewebsschicht (Strato di sostegno) genannt wurde, und unter dieser eine Lage von dicken Bindegewebsfasern, deren maschenförmige Verästelungen nichts anderes als grosse Lymphspalten darstellen (Fig. 8 und 10). An den Stellen nun, an welchen der Peritonäalüberzug des Zwerchfells im Stande ist, körnige Substanzen aufzunehmen, also in der Zona peritendinea und im Centrum tendineum, bemerkt man, dass die Bündel der Stützgewebsschicht, weite Lücken zwischen sich lassend, brückenförmig über die Lymphspalten hinwegziehen, und dass die Membrana limitans gerade im Gebiete dieser Lücken von einer Anzahl Oeffnungen durchsetzt ist (Fig. 9 und 10). Es würden demnach zwischen der Bauchböhle und den oberflächlichen Lymphspalten der Serosa Stellen freier Communication bestehen, wenn das Endothellager, welches einerseits die Peritonäaloberffäche, andererseits die Lymphräume auskleidet, nicht vorhanden wäre. Feinkörnige Substanzen, welche mit dem herausgenommenen menschlichen $Z$ werchfell in Berührung gebracht wurden, drangen, wie Bizzozero und Salvioli beobachten konnten, in die Lymphspalten der Serosa nur im Gebiete der Zona peritendinea und tendinea ein, also nur an den Stellen, an welchen die Membrana limitans die beschriebenen Oeffnungen besitzt.

So war also für das Absorptionsvermögen des Centrum tendineum und der Zona peritendinea eine ausreichende Erklärung gewonnen. Mein Bestreben war es, die von Bizzozero und Salvioli am Zwerchfell angestellten Forschungen durch die anatomische Untersuchung der übrigen Theile des Peritonäum zu vervollständigen. Da jedoch die Bearbeitung des Bauchfells in seiner Gesammtheit eine äusserst zeitraubende Aufgabe ist, so 
habe ich mich darauf beschränkt, die oberflächlichen Schichten der Serosa, das Endothel und die Membrana limitans zu studiren, da diese für einen etwaigen Durchtritt von Körnchen in erster Linie von Bedeutung sind. Diese Einschränkung meiner Untersuchung schien mir um so gerechtfertigter, als durch Bizzozero's Entdeckung der Oeffnung in der Membrana limitans zur Genüge bewiesen ist, dass gerade dieser Membran eine wichtige physiologische Aufgabe zukommt.

1. Das Endothe ${ }^{1}$ ). - Zum Studium der Endothelschicht dienten mir frische gut erhaltene Leichen Erwachsener, Neugeborner und Föten; von Thieren benutzte ich die im Laboratorium vorwiegend verwendeten: Hunde, Kaninchen, Meersehweinchen und Mäuse.

Für die Untersuchungen über Gestalt und Aufbau des Endothels reichen die Methoden von Ranvier 1891 (Härtung des Mesenterium von Meerschweinchen in Osmiumsäure, Färbung mit Methylviolett) und von Kolossow 1892-1893 (Härtung in Osmiumsäure und Reduction mit Tannin) im Allgemeinen aus. In der Mehrzahl meiner Untersuchungen zog ich jedoch, obwohl ich mit diesen Methoden zufriedenstellende Resultate erzielt habe, die Härtung in. Müller'scher Flüssigkeit vor, welche in geeigneter Anwendung vorzügliche Ergebnisse liefert und weniger wie jedes andere Verfahren Veränderungen im Protoplasma hervorbringt; kurz, die Müller'sche Flüssigkeit eignet sich zum Studium der Endothelien ganz ausgezeichnet, wie auch Smirnow bei seinen Untersuchungen am Endothel der Descemet'schen Membran bestätigen konnte.

Das von mir vorwiegend angewandte Verfahren war folgendes: Grosse Stücke des menschlichen Peritonäum in Zusammenhang mit den darunter liegenden Muskelschichten werden 12 bis 18 Stunden lang bei $37^{\circ}$ in einer reichlichen Menge Müller'scher Flüssigkeit gehalten, welche während dieses Zeitraums 1-2 mal erneuert wird. Wenn man jetzt mit der Messerschneide

1) Der Ausdruck Endothel ist hier nicht in dem besonderen Sinne von $\mathrm{His}$, welcher unter Endothel eine epitheliforme Bekleidung mesoblastischer Herkunft versteht, sondern einfach der Kürze wegen gebraucht. Bekanntlich sind die Embryologen noch nicht ganz einig darüber, ob das pleuroperitonäale Epithel meso- oder endoblastiscben Ursprungs ist. 
über die Serosa streicht, so gelingt es nicht schwer, verhältnissmässig grosse Fetzen des völlig isolirten Endothels zu erhalten; dieselben sind zunächst ganz zusammengeschrumpft, lassen sich jedoch unter der Lupe in einem Tropfen Wasser entfalten.

Sehr schöne Bilder erhält man, wenn man diese auf dem Objectträger ausgebreiteten Endothelstücke mit einer starken Lösung von saurem Fuchsin 1-2 Stunden lang färbt und nach Entfernung des überschüssigen Farbstoffs in Wasser untersucht, oder wenn man sie mit Pikrocarmin oder starker wässriger Eosinlösung färbt und dann in 33 procentiger Lösung von essigsaurem Kali betrachtet. Die Behandlung mit saurem Fuchsin hat den Vorzug, dass Protoplasma tiefroth zu färben, während die oberflächlichen Lamellen nur einen zart rosarothen Ton annehmen, so dass ihre Ränder sich gut von einander abheben.

Bei den Thieren verfuhr ich ebenso, nur wurde hier die Bauchhöhle unmittelbar nach der Tödtung geöffnet und mit warmer Müller'scher Flüssigkeit angefüllt, so dass die Abtragung des Bauchfells unter dem Flüssigkeitsspiegel stattfand; wie bei den Untersuchungen an menschlichen Leichen wurde auch hier Sorge getragen, eine dicke Schicht der musculären Unterlage mitzunehmen, um so Zerrungen und Verschiebungen im Zellenverband $\mathrm{zu}$ vermeiden.

In Bezug auf die äussere Form und den Bau der Endothelzellen konnte ich mehrere, bereits von älteren Forschern beschriebene Befunde bestätigen.

Wie schon vor geraumer Zeit Rindfleisch, Bizzozero (1876), Tourneaux (1874-1876) und neuerdings noch genauer Ranvier (1891) und Kolossow (1892-1893) beschrieben haben, setzt sich die Endothelzelle des Peritonäum aus einer oberflächlichen, äusserst dünnen, homogenen Schicht (Lamella superficialis) und aus einer tieferen, dickeren Schicht zusammen, welche vom Protoplasma mit dem Kern gebildet wird. Das Protoplasma ist von leicht körnigem Aussehen, besonders in der nächsten Umgebung des Kernes; letzterer ist gewöhnlich bläschenförmig oder oval und enthält $1-2$ Kernkörperchen.

Die Lamella superficialis (Deckepithel nach Kolossow), welche den Cuticularbildungen anderer Zellen, z. B. des Darmepithels, an die Seite zu setzen ist, überragt mit ihren Rändern 
die Grenzen der Protoplasmaschicht, doch entsendet das Protoplasma einige feine Fortsätze, welche man in den isolirten Zellen (Fig. 1) den freien Rand der Lamella erreichen sieht; während also die letatere eine annähernd polygonale Gestalt hat, besitzt die Protoplasmaschicht einen fast strahligen Umriss. Betrachtet man die Endothelschicht im Zusammenhang, so sieht man (Fig. 2), wie die an einander grenzenden Ränder der oberflächlichen Lamellen sich gegenseitig berühren, während die feinen protoplasmatischen Fortsätze mit den gleichen Fortsätzen der Nachbarzelle in Verbindung treten. So bietet das Endothel des Peritonäum ein weiteres Beispiel für die in anderen Organen und Geweben ${ }^{1}$ ) schon mehrfach gefundene Art der Zellverbindung durch Protoplasmabrücken, welche Heizmann und Pflüger Veranlassung gab, die kühne Hypothese eines organischen Zusammenhanges zwischen sämmtlichen Zellen des thierischen Körpers aufzustellen.

Im Vorübergehen möchte ich noch auf eine von Paladino (1883) und Kolossow (1893) zuerst bemerkte Eigenthümlichkeit im Bau der Serosa-Endothelien hinweisen, ich meine das Vorkommen kurzer feiner Wimpern an ihrer freien Oberfläche. Behandelt man Theile des serösen Ueberzugs der Leber und der Milz von Meerschweinschen nach Kolossow und untersucht sie dann in dünnen verticalen Schnitten, die in Glycerin oder Lösung von essigsaurem Kali eingebettet sind, so sieht man auf der freien Oberfläche der Endothelzellen deutlich zahlreiche kurze feine Wimpern der Lamella superficialis aufsitzen, wie es in der mittelst Abbe'scher Camera lucida entworfenen Fig. 3 dargestellt ist. An der frischen Serosa dagegen ist es mir nie gelungen, diese Anhänge deutlich za sehen. Auch bei Benutzung des heizbaren Objecttisches nach Schultze konnte ich die von Paladino beschriebenen Schwingungen der Wimpern niemals beobachten, selbst wenn ich die von diesem angerathene 0,45 procentige Chlor-

1) Diese Art der Verbindung wurde nachgewiesen im Epithel des Stratum Malpighi (Bizzozero), im Basaltheil des Dünndarmepithels (Heidenhain), im Epithel der Descemet'schen Membran (Cornil und Nüel, Smirnow), zwischen den. Epithelzellen des Follikels und der Eizelle durch die Poren der Zona pellucida hindurch (Flemming, Retzius, Paladino), bei den glatten Muskeizellen (Barfurth u. A.) und bei den Muskeln der Insecten (Kölliker). 
natriumlösung anwandte, der ich übrigens die von dem genannten Forscher nachgerühmten Vorzüge nicht zugestehen kann.

Eingehender als mit dem Bau der einzelnen Zelle habe ich mich mit den gegenseitigen Beziehungen der Zellen beschäftigt, und zwar besonders hinsichtlich der Frage, ob zwischen den Zellen präformirte Oeffnungen (Stigmata oder Stomata) vorhanden sind. Diese Frage wurde durch die ersten Veröffentlichungen von v. Recklinghausen, wonach die Lymphgefässe der Serosa durch besondere Oeffnungen in der Epithelschicht mit der Bauchtöhle in Verbindung stehen sollten, aufgeworfen und ist bis jetzt noch nicht entschieden. Es möge genügen, auf zwei neuere Arbeiten, die von Kolossow and von Beck hinzuweisen, welche gleichzeitig zu ganz entgegengesetzten Schlüssen gelangt sind: jener leugnet das Vorkommen solcher Oeffnungen gänzlich, dieser findet sie in grosser Anzahl und glaubt mit leichter Mühe den Beweis führen zu können, dass sie die peritonäalen Mündungen der Lymphgefässe darstellen.

Eine Reihe von Forschern, welche hier nicht aufgezählt werden sollen, hält an der Existenz der Stomata fest, während eine nicht minder grosse Anzahl die von jenen als Stomata angesprochenen Bilder für Kunstprodukte oder zufällige Bildungen erklärt.

Das schon seit 30 Jahren immer wieder angewandte klassische Verfahren der Inprägnation mit Silbersalzen diente auch mir bei einer Reihe der in dieser Richtung angestellten Untersuchungen. Die mittelst Durchschneidung des Bulbus getödteten Kaninchen wurden (nach dem Verfahren von Ludwig) durch einen im cranialen Drittel des Abdomen angelegten Querschnitt in zwei Theile zerlegt, wobei Zerrungen des $Z$ werchfells sorgfältig vermieden wurden. Jetzt wurde die peritonäale Fläche des Zwerchfells rasch mit einem dünnen Strahl destillirten Wassers gewaschen, darauf einige Minuten lang im Dunkeln mit einer 1 pro mille Lösung von Silbernitrat berieselt und nach Auswaschung des Silberüberschusses mit gewöhnlichem, mehrfach erneuertem Alkohol übergossen. Nach wenigen Minuten hatte das Zwerchfell unter dem Einflusse des Alkohols eine gewisse Festigkeit erlangt, welche erlaubte, dasselbe ohne wesentliche Zerrungen und Verschiebungen herauszunehmen. Auch die übrigen 
Theile des Bauchfells (Netz, Mesenterium, Ligamentum latum) wurden in situ mit einer reichlichen Menge der Silbersalzlösung überrieselt.

Dasselbe Verfahren wandte ich bei menschlichen Fötus an. Beim Erwachsenen wurden grosse Stücke des Bauchfells aus der Leiche herausgenommen und so bald wie möglich mit dem Silbersalz behandelt. Ich erhielt mit dieser Methode sehr schöne Präparate, in welchen die Form der Zellen und ihre gegenseitigen Beziehungen deutlich zu erkennen waren.

Wie von allen Beobachtern übereinstimmend angegeben wird, bilden die durch den Niederschlag von Silberalbuminat sichtbar gemachten Zellgrenzen mehr oder weniger unregelmässige Vielecke: zuweilen zeigen diese Zellen jedoch auch Fortsätze (Fig. 4), welche manchmal eine grosse Länge erreichen (bis zu $70 \mu$ ). Solche mit Fortsätzen versehene Zellen, welche nach Bizzozero im menschlichen Peritonäum in geringer Menge vorkommen, habe ich bei Thieren in verhältnissmässig grosser Anzahl gefunden, ganz besonders bei Meerschweinchen.

So sorgfältig man jedoch auch durch die Auswaschung mit destillirtem Wasser die Peritonäalflüssigkeit zu entfernen, so vorsichtig man jede Zerrung zu vermeiden gesucht hat, stets findet man selbst in gut gelungenen Präparaten hier und da an der Vereinigungsstelle $z$ weier oder mehrerer Zellen kleine rundliche oder leicht ovale Punkte, an welchen eine stärkere Ausfällung von Silberalbuminat stattgefunden hat, kurz, wir haben hier Bilder vor uns, welche ganz mit den als Stigmata oder Stomata beschriebenen übereinstimmen. Wenn nun durch Zufall bei der Präparation eine auch noch so leichte Zerrung stattgefunden hat (was bei dem Verfahren v. Recklinghausen's, bei welchem das Peritonäum mittelst Stecknadeln auf Korkringen aufgespannt wird, kaum zu vermeiden ist), so finden sich diese Bildungen in grösserer Anzahl, die an den Stellen stärkster Zerrung, wie in der Nähe der Stecknadeln, sehr beträchtlich werden kann.

Bei meinen Versuchen erhielt ich eine Reihe von zweifelhaften Ergebnissen, d. h. Präparate mit Silberniederschlägen, die trotz ihrer geringen Anzahl und unregelmässigen Vertheilung wohl als Stomata hätten aufgefasst werden können; aber neben diesen $\mathrm{zweifelhaften} \mathrm{Resultaten}$ bekam ich, besonders nachdem 
ich mich in der Technik vervollkommnet hatte, eine Reihe von durchaus klaren und einwandfreien Bildern, in welchen die dicht an einander geschlossenen Zellen ohne irgend welche Lücke sich in ganzer Ausdehnung berühren. So besitze ich einige $1 \mathrm{qcm}$ grosse Stücke vom $Z$ werchfell des Kaninchens, welche keine Spur dieser Bildung aufweisen (Fig. 5).

Da nun in dieser Frage, in welcher die zweifelhaften Ergebnisse durch eine unvollkommene Technik bedingt sein können, die nach einer Seite hin beweisenden Präparate den Ausschlag geben müssen, so fühle ich mich zu der Behauptung berechtigt, dass normaler Weise zwischen den Endothelzellen des Peritonäum keine Stomata vorhanden sind.

Die Richtigkeit dieser Thatsache wird durch die in Müller'scher Flüssigkeit gehärteten und mit saurem Fuchsin gefärbten Präparate bestätigt. Ja noch mehr, hier finden wir auch die Erklärung für das Auftreten der stomataähnlichen Bildungen.

Bei der mikroskopischen Durchmusterung eines solchen Präparates sieht man, wie oben beschrieben, die Endothelzellen mit ihrer Deckplatte in vollständigem, ununterbrochenem $\mathrm{Zu}$ sammenhang, während sie in der darunterliegenden Schicht durch die protoplasmatischen Fortsätze in Verbindung stehen. Hier und dort bemerkt man jedoch eine eigenthümliche Anordnung (Fig. 6), indem nehmlich an der Vereinigungsstelle von 3 oder 4 Zellen diese Protoplasmabrücken fehlen, so dass es den Anschein hat, als ob sich der Protoplasmaleib an dieser Stelle etwas retrahirt hätte. Wir haben hier also eine grosse rundliche Lücke zwischen dem Protoplasma von 3-4 benachbarten Zellen vor uns, doch ist diese Lücke auf der Bauchhöhlenseite durch die Ecken der in enge Berührung tretenden oberflächlichen Lamellen überdeckt. Bei dieser, meines Wissens bis jetzt noch nicht beschriebenen eigenthümlichen Anordnung liegt es auf der Hand, wie leicht während der Einwirkung der Silbersalzlösung, selbst beim geringsten Flüssigkeitsdruck, die durch keine protoplasmatische Unterlage gestützten Ecken der Lamellen auseinander weichen können, worauf an diesen Stellen eine grössere Menge des Silberniederschlags gebildet wird.

Als weitere bemerkenswerthe Thatsache lässt sich bei diesem Verfahren die Gegenwart von Leukocyten zwischen den 
Endothelzellen des Peritonaeum diaphragmaticum nachweisen (Fig. 7). Diese Beobachtung war schon von Bizzozero an der menschlichen Peritonäalserosa gemacht worden, doch liess der Befund, da er sich auf Leichentheile bezog, den Einwand offen, dass er durch örtliche oder allgemeine, mit dem blossen Auge noch nicht nachweisbare Veränderungen im Bauchfell bedingt gewesen sei. Wir können dagegen behaupten, dass der Durchtritt von Leukocyten zwischen den Endothelzellen des Peritonaeum diaphragmaticum bei vollständig gesunden Thieren ein regelmässiger Vorgang ist; besonders beim Hunde lässt sich an grossen Stücken isolirten Endothels unzweifelhaft nachweisen, dass die Leukocyten thatsächlich zwischen den Endothelzellen liegen. Die Form dieser Leukocyten ist wechselnd (Fig. 7a u. b); sie ist rundlich, birnförmig oder unregelmässig am Berührungspunkt von mehreren, biscuitförmig an der Berührungslinie von zwei Endothelzellen. Von dieser Beobachtung am Hunde dürfen wir den Schluss ableiten, dass auch beim Menschen physiologischer Weise ein Durchtritt von Leukocyten durch die Endothelbekleidung des Zwerchfells stattfindet. Es ist jedoch $z u$ beachten, dass in pathologischen Fällen, z. B. schon bei leichten Circulationsstörungen in den Organen der Bauchhöhle, die Zahl der Leukocyten beträchtlich anwächst.

Der Durchtritt der Leukocyten zwischen den Endothelzellen der Serosa liefert übrigens noch eine weitere Erklärung für das Auftreten von stomataähnlichen Bildungen bei der Behandlung mit Silbersalzen auch in solchen Präparaten, welche mit der grössten Sorgfalt behandelt worden sind. Es ist denkbar, dass an diesen Stellen vor Kurzem Wanderzellen hindurchgetreten sind und die auseinander gedrängten Endothelzellen, bezw. deren oberflächliche Lamellen, sich zur Zeit der Versilberung noch nicht wieder zusammengeschlossen haben.

2. Die Membrana limitans. - Durch Bizzozero (1873-74) ist festgestellt worden, dass die serösen Häute des Menschen von einer äusserst dünnen Bindegewebsschicht, der von ihm so genannten Membrana limitans (Grenzmembran), begrenzt werden, auf welcher das Epithel ruht, dass sie also ganz ähnliche Verhältnisse aufweisen, wie sie für die Thiere von Anderen besçrieben worden sind (Wodd). Bizzozero schildert diese Schicht 
als einer feinkörnige oder feingestreifte, keine Zellen enthaltende Membran, welche mit Essigsäure aufquillt und unsichtbar wird. Doch sind diese fundamentalen Merkmale durchaus nicht an allen serösen Häuten und an den verschiedenen Stellen derselben Serosa gleich ausgesprochen, eine Thatsache, die bezüglich des Peritonaeum diaphragmaticum, der Pleura und des Pericard von Bizzozero and Salvioli, bezüglich der Tunica vaginalis testis von Vincenzi festgestellt ist.

Eine äusserst wichtige Struktureigenthümlichkeit ist das bereits erwähnte Vorkommen von Oeffnungen an gewissen Stellen der Grenzmembran. Ausser im Gebiet der Zona peritendinea und tendinea des Bauchfells sind diese Oeffnungen nach Bizzozero und Salvioli auch in der Zona peritendinea der Zwerchfellpleura, an der Pleura parietalis und an bestimmten Punkten der Pleura pulmonalis, nehmlich an den Vereinigungsstellen der einzelnen Lungenläppchen, vorhanden. Dagegen steht fest, dass an der Serosa des Epi- und Pericard, im peripherischen und centralen Theil der Zwerchfellpleura (Bizzozero und Salvioli), sowie an der Scheidenhaut des Hodens (Vincenzi) diese Oeffnungen vollständig fehlen.

Die Poren der Grenzmembran des Peritonaeum diaphragmaticum (vergl. die von Bizzozero und Salvioli entliehenen Figuren 9 und 10) messen $4-16 \mu$ im Durchmesser und haben einen scharf gezeichneten ovalen oder rundlichen Umriss. Sie stehen zu je 50-60 in Gruppen von unregelmässiger oder eiförmiger Gestalt, welche den Lücken in der netzförmigen Schicht entsprechen. Im Gebiet der durchlöcherten Stellen ist die Grenzmembran mit der Stützgewebsschicht inniger verwachsen, so dass beim Versuch, die Grenzmembran zu isoliren, an diesen Stellen zahlreiche Fasern des Stützgewebes hängen bleiben.

Meine eigenen topographischen Untersuchungen an der Membrana limitans beziehen sich auf das Ligamentum latum, den serösen Ueberzug des Darmes, des Magens, der Leber, der Milz, des Pankreas, des Uterus und der vorderen Bauchwand.

Zum Isoliren der Grenzmembran bediente ich mich eines ähnlichen Verfahrens, wie es von Bizzozero angewandt wurde: grosse Stücke der Serosa werden zunächst etwa zwei Tage lang in Müller'scher Flüssigkeit und dann 12-24 Stunden in einer 
Mischung von gleichen Theilen Alkohol und Wasser gehalten; hierauf wird die Endothelschicht mit Hülfe eines Pinsels oder eines starken Wasserstrahles entfernt und um die Grenzmembran mittelst einer feinen Pincette aufzuheben und abzuziehen versucht. Mit einiger Uebung gelingt es, kleinere oder grössere Stücke der Membran, je nach ihrer festeren oder loseren Verbindung mit der Unterlage, in isolirtem Zustand zu erhalten. Diese Stückchen werden unter der Lupe ausgebreitet und mit Eosin oder saurem Fuchsin diffus gefärbt, worauf sie in Lösung von essigsaurem Kali oder in einer Mischung von gleichen Theilen Glycerin und Wasser betrachtet werden.

Die allgemeinen Eigenschaften der Grenzmembran an den von mir untersuchten Stellen stimmen mit den Angaben von Bizzozero überein. Mit Ausnabme von einigen Stellen, wie an der Basis des Ligamentum latum, woselbst die Membran homogen erscheint, bietet sie im Allgemeinen eine äusserst feine, fibrilläre Struktur, die an der Leber, an der Milz und am Uterus besonders deutlich ist. Um den fibrillären Bau besser zu erkennen, bedarf es der Untersuchung in schwach brechenden Medien, wie einfaches Wasser oder essigsaures Kali.

Bei der genaueren topographischen Untersuchung, zu welcher ich möglichst grosse Stücke benutzte, zeigte sich die Membran als durchweg zusammenhängend, ohne eine Spur von Oeffnungen, welche den so leicht nachweisbaren Poren am Peritonaeum diaphragmaticum und an manchen Punkten der Pleura an die Seite zu stellen wären. Ich kann demnach behaupten, dass die Membrana limitans in dem ganzen von mir untersuchten Gebiete des Bauchfells (Ligamentum latum, Darm, Magen, Leber, Milz, Pankreas, Uterus und vordere Bauchwand) keine Oeffungen besitzt.

Die Benutzung des Wasserstrahls an Stelle des Pinsels zur Entfernung des Endothels hat den Nachtheil, dass diese Schicht nicht vollständig beseitigt wird, andererseits bietet sie den Vortheil, gewisse feinere Einzelheiten in der Anordnung der Membrana limitans erkennen zu lassen, die bei Anwendung des weniger zarten Pinselverfahrens zerstört werden.

Die von mir auf diese Weise zur Ansicht gebrachte Struktureigenthümlichkeit, welche meines Wissens von anderen Beob- 
achtern noch nicht beschrieben ist, besteht in Folgendem: Auf der Oberflächenseite der Grenzmembran (Fig. 11) finden sich äusserst zarte lineare Leisten von homogenem Aussehen, welche mit ihren Enden so zusammentreten, dass sie leicht vertiefte, polygonale Räume von der Form und Grösse der Endothelzellen umgrenzen. Diese Leisten bilden zusammen Figuren, welche an die bei der Imprägnirung des Endothels mit Silbersalzen erhaltenen Bilder erinnern. Da nun bei dem eingeschlagenen Verfahren hier und da einige Endothelzellen an ihrem Platze geblieben sind, lässt sich ohne Mühe erkennen, dass die von den Leisten umgrenzten, leicht vertieften Räume, die gleichsam einen Abdruck der Zellen darstellen, nichts anderes sind als Nischen, in welchen die Endothelzellen eingebettet liegen. Am deutlichsten lässt sich dies an solchen Präparaten erkennen, in welchen aus dem noch erhaltenen Endothellager eine oder zwei Zellen herausgefallen sind (Fig. 11).

Diese Anordnung ist an verschiedenen Stellen des menschlichen Peritonäum nachweisbar, aber am leichtesten gelingt die Beobachtung an Punkten, an welchen die Grenzmembran etwas dicker ist, und, wie z. B. über der Leber, auf fester Unterlage aufruht. Ich möchte jedoch nochmals darauf hinweisen, dass die Präparation die äusserste Zartbeit erfordert, und dass z. B. nach mehrmaligem Darüberstreichen mit dem Pinsel die beschriebenen Einzelheiten nicht mehr erkennbar sind.

Meine Versuche, die Leisten der Grenzmembran auch in verticalen Schnitten zur Darstellung zu bringen, sind ohne Erfolg geblieben; ob die Reliefs durch die verschiedenen zum Schnittverfahren nöthigen Manipulationen zerstört werden oder ob sie nur zu geringfügig sind, um im Querschnitt erkennbare Bilder zu liefern, lasse ich dahingestellt.

Nur kurz sollen hier noch einige Besonderheiten, welche die Grenzmembran in ihren Beziehungen zu den darunterliegenden Gewebsschichten darbietet, erwähnt werden.

Die Isolirbarkeit der Limitans, welche von der Festigkeit der Verbindung zwischen der Membran und dem Stützgewebe oder den tieferen Bindegewebsschichten abhängt, ist in den einzelnen Gebieten des Peritonäum verschieden. Sehr leicht gelingt die Isolirung an der Serosa des Darmes, und zwar vorwiegend 
in querer Richtung, so dass man keine quadratischen Stücke, sondern ganz schmale lange Streifchen (von 1-1 $1 \frac{1}{2} \mathrm{~cm}$ Länge auf 1-2 mm Breite) erhält. Zum genauen Studium der topographischen Beziehungen ist es daher erforderlich, an jedem zur Untersuchung kommenden Darmabschnitt mehrere benachbarte Streifen der Membran abzuziehen. In den günstigsten Fällen gelingt es, sie ganz zu isoliren und sich davon zu überzeugen, dass sie äusserst dünn, aber überall zusammenhängend und von ganz leicht fibrillärer Beschaffenheit ist. Häufig jedoch bleiben an ihrer unteren Fläche Reste der Stützgewebsschicht zurück, welche aus weitmaschig verflochtenen elastischen und feinen Bindegewebsfasern mit grossen Zellen besteht; diese Bindegewebszellen besitzen einen grossen ovalen Kern und lange protoplasmatische Fortsätze, welche, vielfach verästelt, mit gleichen Fortsätzen der benachbarten Zellen in Verbindung treten. Aehnliche verästelte Bindegewebszellen hat Vincenzi in der Scheidenhaut des Hodens beschrieben.

Am serösen Ueberzug des Magens sind die Verbindungen zwischen der Grenzmembran aus den tieferen Gewebsschichten viel fester, so dass Stücke der letzteren stets daran hängen bleiben und nur an den Rändern des abgezogenen Stückchens kleine Theile der isolirten Membran sichtbar sind. Die Beschaffenheit der letzteren und der oberflächlichen Bindegewebsschicht ist dieselbe wie am Darm, nur bilden die elastischen und Bindegewebsfasern des Stützgewebes ein engeres Netz.

An der Leber, der Milz und dem Uterus ist die Grenzmembran so fest mit dem Stützgewebe verwachsen, dass sie sich nur in ganz kleinen Stückchen isoliren lässt; man muss daher zur topographischen Untersuchung eine Reihe von benachbarten Stückchen verwenden. Die Membran ist hier etwas dicker, als am Darm und die fibrilläre Streifung ist deutlich ausgesprochen. Das. Stützgewebe ist reich an elastischen und Bindegewebsfasern und steht mit der tiefen Schicht in fester Verbindung.

Am Pankreas ist der seröse Ueberzug sehr dünn, so dass es erst nach vielen Versuchen gelang, die Limitans zu isoliren, welche hier von äusserster Feinheit ist und stets noch Fasern der darunterliegenden Bindegewebsschicht trägt. 
Am Peritonaeum parietale ist die Grenzmembran ziemlich leicht $\mathrm{zu}$ isoliren; das Ligamentum latum bietet die Eigenthümlichkeit, dass sich an seiner Basis die Membran ganz leicht abziehen lässt, während sie nach oben $z \mathfrak{u}$ in immer festere Verbindung mit der Unterlage tritt.

Die ausgeführten Untersuchungen an der Membrana limitans haben demnach ergeben, dass an den von mir untersuchten Stellen des Bauchfells die Membran keine Oeffnungen hat, folglich auch eine Aufnahme von Fremdkörpern hier nicht wohl möglich ist. Die Ergebnisse der mikroskopischen Forschung stehen also mit den Resultaten der im ersten Abschnitt wiedergegebenen Thierversuche in Uebereinstimmung.

Freilich ist die Untersuchung nicht auf die ganze Oberfläche des Peritonäum ausgedehnt worden; einige Stellen desselben, wie z. B. der seröse Ueberzug des Netzes, sind diesem topographischen Verfahren nicht zugänglich; andere, wie die Serosa der dorsalen Bauchwand und des Beckens, unterscheiden sich nicht wesentlich von anderen, die der Untersuchung unterworfen worden sind (Basis des Ligamentum latum, vordere Bauchwand u. s. w.). Von der Untersuchung des Mesenterium endlich glaubte ich im Hinblick auf einen alten, durch Ranvier bestätigten Versuch von Bichat Abstand nehmen zu können. Dieser Versuch, den ich mit dem gleichen Erfolg wiederholte, besteht darin, dass das Mesenterium durch ein eingeführtes feines Röhrchen mit Luft aufgeblasen wird. Es bilden sich grosse, lange Zeit stehen bleibende Luftblasen, welche das Mesenterium in eine, die Gefässe und Nerven enthaltende Schicht und in eine feine, gefässlose, mit dem Endothel bekleidete Membran zerlegen. Da diese Membran beim Aufblasen bald auf der einen, bald auf der anderen Fläche des Mesenterium auftritt, so kann sie kaum etwas anderes sein als eben die Membrana limitans mit ihrem Endothel. Dass sie keine Oeffnung besitzt, lässt sich aus dem langen Bestehenbleiben der Luftblasen schliessen, wie ja auch am $Z$ werchfell im Gebiete der Zona muscularis, wo die Poren fehlen, die unter die Grenzmembran eingeblasene Luft in Blasen stehen bleibt. 
III. Ueber den Mechanismus der Aufsaugung.

Wie die im ersten Abschnitt wiedergegebenen Versuche gezeigt haben, treten feinkörnige Stoffe (Chinesische Tusche, Carmin) oder kleine weiche, modellirbare Körper (rothe Blutkörperchen), welche in die Bauchhöhle eingeführt werden, mit grosser Schnelligkeit durch das Zwerchfell hindurch. Es fragt sich nun, welches sind die näheren Umstände dieses Aufsaugungsvorganges?

v. Recklinghausen, welcher mit dem herausgenommenen Zwerchfell von Kaninchen experimentirte (Aufgiessen von Milch auf die peritonäale Fläche und Betrachtung unter dem Mikroskop), glaubte, dass die Milchkügelchen durch die Stomata der Endothelschicht in die Lymphspalten des $Z$ werchfells eintreten. Nach meinen oben dargelegten Untersuchungen, aus welchen die Nichtexistenz solcher Oeffnungen hervorgeht, kann ich mich jedoch dieser Anschauung nicht anschliessen.

In der Absicht, über den Mechanismus der Aufsaugung genaueren Aufschluss zu erhalten, führte ich die verschiedenartigsten Fremdkörper in die Bauchhöhle ein, indem ich dabei von der Voraussetzung ausging, dass der. Aufsaugungsvorgang je nach der Beschaffenheit dieser Körper verschieden ausfallen würde. Dass diese Voraussetzung nicht unbegründet war, lehren die folgenden Ergebnisse.

Betrachten wir zunächst vergleichsweise die mit Carmin und die mit rothen Blutkörperchen angestellten Versuche.

Wenn man 10 Minuten nach Einbringung einer Carminaufschwemmung in die Bauchhöhle die retrosternalen Lymphdrüsen mikroskopisch untersucht, so bemerkt man in den Lymphräumen zahlreiche Carminkörnchen, welche zum Theil frei, zum Theil in Leukocyten eingeschlossen sind; einige wenige Körnchen finden sich auch im Innern der Endothelzellen der Lymphsinus. - Die Flüssigkeit in den zwei grossen retrosternalen Lymphgefässen, welche dem Verlauf der Arteria mammaria interna folgen, hat eine gesättigte rosarothe Färbung, welche durch die Gegenwart von freien, zum kleinen Theil auch in Wanderzellen eingeschlossenen Carminkörnchen bedingt wird. Bemerkenswerth ist jedoch, dass die farblosen Zellen in der Lymphe weit über die Norm vermehrt 
und sämmtlich mit Carminkörnchen beladen sind. Bei der Untersuchung der Flüssigkeit in der Bauchhöhle, sowie des feinen Niederschlages, welchen die Aufschwemmung auf der Fläche der Serosa gebildet hat, sieht man zwischen freien Körnchen auch eine Anzahl von carminbeladenen Wanderzellen. Die grösste Menge der letzteren ist in der von der hinteren Fläche des grossen Netzes mittelst einer Pipette oder durch sorgfältiges Abschaben gewonnenen Flüssigkeit enthalten.

Genau dieselben Verhältnisse trifft man bei dem Versuch mit rothen Blutkörperchen. Es erhellt aus diesen Beobachtungen, dass den Leukocyten eine wichtige Aufgabe bei der Aufsaugung durch das Peritonäum zufällt: sie beladen sich an allen Stellen der Bauchhöhle mit den Körnchen und wandern gegen das Zwerchfell zu, vielleicht unterstützt von der Flüssigkeitsströmung, welche nach dem Ergebniss eines im ersten Abschnitt angeführten Versuches normaler Weise in der Bauchhöhle vorhanden ist.

Es ist nun leicht verständlich, dass diese Wanderzellen eine gewisse Anzahl von Körnchen durch das Zwerchfell hindurch befördern, aber wie kommt der Durchtritt der freien Körnchen zu Stande, welche wir so zahlreich in den retrosternalen Lymphgefässen angetroffen haben?

Obgleich es nicht immer empfehlenswerth ist, sich auf Analogien zu stützen, so glaube ich doch hier an gewisse Thatsachen erinnern zu dürfen, welche an den Blutcapillaren beobachtet sind. v. Recklinghausen, Hoffmann, Aufrecht, Ponfick, Arnold u. A. haben gezeigt, dass feine, in den Blutstrom eingeführte Körnchen die Wand der Blutcapillaren durchwandern können, indem sie sich zwischen zwei Endothelzellen hindurchdrängen. Neuerdings hat Thoma (1893) am Mesenterium des Hundes beobachtet, dass zuweilen während der auf den Durchtritt von Leukocyten folgenden Diapedese rothe Blutkörperchen plötzlich in starkem Strahle durch eine Spalte zwischen zwei Endothelzellen austreten, worauf sich diese Oeffnung wieder schliesst; dieser Vorgang beschränkt sich nach Thoma auf solche Stellen der Gefässwand, an welchen vorher eine Reihe von Leukocyten hindurchgetreten sind.

In analoger Weise können wir meines Erachtens auch den Durchtritt freier Körnchen durch die Endothelschicht, des 
Bauchfells erklären; zum Theil mögen sich dieselben zwischen den Endothelzellen hindurchdrängen, zum Theil auch in Form eines stärkeren Strahles an den durch den Durehtritt der Wanderzellen geschaffenen Oeffnungen der Endothelschicht einströmen, so lange, bis sich die Zellen an diesem Punkte wieder eng zusammengeschlossen haben.

Ausser diesen feinen oder schmiegsamen Körperchen kann das Peritonäum jedoch auch, wie schon Auspitz gezeigt hat; grössere starre Körper, z. B. Stärkekörnchen, aufnehmen, welche keinerlei Formveränderungen einzugehen im Stande sind. Zu meinen Versuchen in dieser Richtung benutzte ich Weizenmehl, dessen Körnchen beträchtliche Grössenunterschiede (von $4-45 \mu$ Durchmesser) darbieten. Die Stärkekörnchen haben ausserdem noch den Vortheil, dass sie sich durch die bekannte Jodreaction leicht von Körnchen anderer Herkunft unterscheiden lassen. Das Mehl wurde in einer auf $37^{\circ}$ erwärmten, mit physiologischer Kochsalzlösung bereiteten Aufschwemmung in die Bauchhöhle von Kaninchen und Hunden eingespritzt.

Auch in diesem Falle sieht man die Aufsaugung mit überraschender Schnelligkeit eintreten. Schon 10-15 Minuten nach der Einführung in die Bauchhöhle finden sich die Körnchen in den Mediastinaldrüsen, und zwar nicht nur solche von kleinem Umfang, sondern auch grössere und ganz grosse, deren Durchmesser den mancher Endothelzellen erreicht. Wie kommt der Durchtritt unter solchen Verhältnissen zu Stande?

Die Untersuchung des Inhaltes der retrosternalen Lymphgefässe liefert in diesem Falle einen etwas anderen Befund, als in den früheren Versuchen. Die Stärkekörnchen finden sich hier zum grössten Theil in den sehr zahlreichen Leukocyten eingeschlossen; nur eine geringe Anzahl von Körnchen, fast durchweg solche kleinsten Umfangs, sind frei. Jede Wanderzelle enthält ein oder mehrere Körnchen, je nach der Grösse der letzteren, und einige sind geradezu damit überladen (Fig. 12). Die grössten Körnchen jedoch sind nicht von einer einżigen Zelle umschlossen, weil diese nioht genügen würde, sondern zwei, drei und vier Leukocyten haben sich vereinigt, um den Fremdkörper zu umkleiden, dêr so gewissermaassen eine zellige Umhüllung erhalten hat (Fig. 13). 
Auch in der Peritonäalflüssigkeit finden sich die Stärkekörner in derselben Weise von Leukocyten eingehüllt, doch ist immer auch eine Anzahl leerer, noch nicht beladener Wanderzellen vorhanden. An vielen Stellen sind die Mehlkörner zusammengeballt und man sieht diese Ballen von zahlreichen Leukocyten umgeben, von denen einige zwischen die Körnchen einzudringen im Begriffe sind. Auch hier trifft man wieder die meisten Leukocyten in der Umgebung des grossen Netzes an.

Am Endothel des Peritonaeum diaphragmaticum sind während der Aufnahme der Körnchen wichtige Veränderungen nachzuweisen. Es ist rathsam, die Untersuchung desselben in den ersten 15 Minuten vorzunehmen, um noch möglichst normale Verhältnisse anzutreffen und die tiefgreifenden Störungen zu vermeiden, welche die längerdauernde Berührung mit den Fremdkörpern in der Serosa hervorbringt.

An der Endothelschicht bemerkt man (Fig. 14 und 15), sowohl bei der Untersuchung in situ (bei Kaninchen), wie an grossen, nach Härtung in Müller'scher Flüssigkeit gewonnenen Stücken ${ }^{1}$ ), zwischen den Endothelzellen zahlreiche rundliche und ovale Oeffnungen verschiedenen Umfangs, in welchen hier und da noch eine mit Körnchen beladene Wanderzelle oder auch ein freies Körnchen (Fig. 15) angetroffen wird. Diese Oeffnungen entsprechen zumeist der Berührungsstelle von zwei, drei und mehr Endothelzellen, deren Protoplasma im Gebiete der Oeffnung etwas retrahirt ist, so dass ihr Kern an manchen Stellen sehr naho am Rando dieser Oeffnung liegt. Da, wo sich zwischen zwei Endothelzellen eine langgestreckte ovale Oeffnung gebildet hat, sieht man zuweilen mit ganz starker Vergrösserung diese Lücke von ein oder zwei zarten Protoplasmastreifen brückenförmig durchsetzt, durch welche die beiden angrenzenden Zellen noch in Verbindung stehen (Fig. 14).

Die mitgetheilten Beobachtungen berechtigen uns nunmehr, zu behaupten, dass die Aufsaugung der Stärkekörnchen zum grössten Theil durch Vermittelung der Leukocyten zu Stande kommt, während nur einige der kleinsten Körnchen frei durch die von den Leukocyten hinterlassenen Oeffnungen in der

1) Ueber das Verfahren siehe im zweiten Abschnitt .S. 343. 
Endothelschicht hindurchtreten. $O b$ die Endothelzellen activen Antheil an der Bildung der Oeffungen nehmen (vielleicht indem sie sich zusammenziehen), oder ob sie sich nur passiv von den Leukocyten auseinander drängen lassen, möchte ich zur Zeit unentschieden lassen, da mir hierüber keine hinlänglichen Beobachtungen zu Gebote stehen.

Die Ergebnisse meiner Versuche scheinen mir auch deshalb von Interesse zu sein, weil sie einen neuen Beweis dafür liefern, wie schnell die Leukocyten an den Orten auftreten, wo fremde Substanzen in den Organismus eingedrungen sind, und wie rasch sie einzeln oder zu mehreren sich den Fremdkörper einverleiben, um ihn nach den Organen zu bringen, welche für die Ablagerung solcher Eindringlinge bestimmt sind.

Die zahlreichen Leukocyten, welche sich im Verlaufe weniger Minuten in der Bauchhöhle ansammeln, stammen wohl zum grossen Theil aus den Blutgefässen, zum Theil jedoch auch aus den zahlreichen kleinen Lymphfollikeln, die im grossen Netz, im Ligamentum gastro-hepaticum $\mathfrak{u}$. s. w. zerstreut sind. Diese Follikel, welche nach Ausweis der Silberpräparate auf der einen Seite nur von einer einfachen, nicht überall zusammonhängenden Endothelschicht überkleidet sind, haben grosse Aehnlichkeit mit den Lymphfollikeln des Darmes. Es scheint mir daher die Vermuthung nicht ganz ungerechtfertigt, dass die Lymphfollikel des Netzes und des Ligam, gastro-hepaticum physiologischer Weise der Bauchhöhle eine Anzahl von Leukocyten zuführen, wie sie dem Darmlumen von den Follikeln der Darmwand geliefert werden.

\section{Schlussfolgerungen.}

Die von uns gewonnenen Aufschlüsse über den Bau und das Aufsaugungsvermögen des Peritonäum unter normalen Verhältnissen lassen sich in folgenden Sätzen zusammenfassen:

1. Das Diaphragma ist das einzige Gebiet der Serosa, welches für die Aufsaugung körniger Stoffe bestimmt ist. Diese Aufsaugang geht mit äusserster Schnelligkeit vor sich.

2. Es bestehen in der Bauchhöhle beständig gegen das $\mathrm{Zwerchfell} \mathrm{gerichtete} \mathrm{Flüssigkeitsströmungen.} \mathrm{Die} \mathrm{mediastinalen}$ Lymphdrüsen baben die Aufgabe, die aus der Bauchhöhle stammende Lymphe zu sammeln. 
3. Die Endothelzellen der Serosa besitzen zum Theil lange Fortsätze. Sie bilden normaler Weise eine zusammenhängende Schicht ohne irgend welche Oeffnungen. Die als Stigmata oder Stomata beschriebenen Bildungen sind zufällige Produkte. An manchen Stellen können durch Retraction des Protoplasma von zwei oder drei benachbarten Zellen rundliche Räume entstehen, welche an der Oberfläche von der Lamella superficialis überdeckt sind. Zwischen den Endothelzellen finden sich unter gewöhnlichen Verhältnissen hie und da Leukocyten.

4. Die Grenzmembran, welche im Gebiet des Peritonaeum diaphragmaticum durchlöchert ist, besitzt an vielen anderen Stellen der Serosa keine Spur solcher Oeffnungen. Durch feine Leisten auf der Membran werden flache Nischen gebildet, in denen die Endothelzellen eingebettet liegen.

5. Feinkörnige Substanzen (Carmin) und weiche, modellirfähige Körper (rothe Blutkörperchen) durchwandern die Endothelschicht des Zwerchfells zum grössten Theil in freiem Zustande, indem sie sich 2wischen den Endothelzellen hindurchdrängen, zum kleineren Theil als Einschluss von Leukocyten.

Grosse starre Körper (Stärke) werden zum grössten Theil von Wanderzellen durch das $\mathrm{Z}$ werchfell hindurchbefördert; einige derselben, fast ausschliesslich die allerkleinsten, können das Endothel auch durch die von den Leukocyten hinterlassenen Oeffnungen durchwandern. Der Durchtritt der grössten dieser Körnchen geschieht durch Vermittelung von Leukocyten, welche sich an der Oberfläche des Fremdkörpers ausbreiten und ihn so in eine contractile Protoplasmaschicht einhüllen.

\section{L i t e r a t u r.}

Auspitz, B., Ueber die Resorption ungelöster Stoffe bei Säugethieren. Stricker's Medic. Jahrbücher. Jahrg. 1871. Heft 3. S. 284 (304). Beck, A., Ueber die Aufsaugung fein vertheilter Körper aus den serösen Höblen. Wien. klin. Wochenschr. 1893. No. 46.

Bizzozero, Centralbl. f. d. med. Wissensch. 1874.

-, Osservatore delle cliniche. Dicembre 1873.

Bizzozero e G. Salvioli, Sulla struttura $\theta$ sui linfatici del peritoneo diaframmatico. Arch. per le Scienze med. anno I. 1876.

- - Sulla struttura e sui linfatici della pleura e del pericardio. Arch. per le Scienze med. anno II. 1878 , 
Dubar et Remy, Sur l'absorption par le péritoine. Journ. de l'Anatomie et de la Phys. Année XVIII. 1882.

Kolossow, Struktur des Endothels der Pleuroperitonäalhöhle. Biologisches Centralbl. 1892. S. 87.

-, Aich. f. mikr. Anat. Bd. XLIL. 1893.

Ludwig und Schweigger-Seidel, Ueber das Centrum tendineum des Zwerchfelles. Verhandl. der Gesellsch. d. Wissensch. zu Leipzig. November 1866.

Maffucci, Sull' assorbimento del peritoneo. Gionale internazionale delle Scienze med. Anno IV. 1882.

-, Sulla patologia del peritoneo. Il movimento medico-chirurgico. Anno XV. Napoli 1883.

Paladino, Arch. italiennes de biologie. III. 1883.

Ranvier, De l'endothélium du péritoine, ete. Comptes rendus de l'Acad. des Sciences. CXII. 1891.

-, Traité technique d'histologie. 20 éd. 1889.

v. Recklinghausen, Zur Fettresorption. Dieses Archiv. Bd. 26.

Tourneux, Recherches sur l'épithélium des sérenses. Journ. de l'Anatomie. 1874.

Tourneux et Hermann, Recherches sur quelques épithéliums plats. Journ. de l'Anatomie. 1876.

Thoma, Histogenese und Histomechanik des Gefässsystems. 1893.

-, Lehrbuch der pathologischen Anatomie. 1894.

-, Dieses Archiv. Bd. 74.

Vincenzi, Sulla struttura e sui linfatici della tunica vaginale. Arch. per le Scienze med. vol. VI.

Werig 0, Les globules blanes protecteurs du sang. Ann. de l'Inst. Pasteur. 1892.

\section{Erklärung der Abbildungen. \\ Tafel VII.}

Alle Zeichnungen sind mit der Camera lucida nach Abbe, Papier in der Höhe des Objectes, entworfen. - Mikroskop Koristka.

Fig. 1-2. Isolirte Endothelzellen vom normalen menschlichen Peritonaeum. Vergr. 1250 (S. Ap. $\frac{1}{15}$, Oc. comp. 8).

Fig. 3. Endothelzellen rom serösen Ueberzug der Meerschweinchenmilz. (Osmiumsäure, Tannin-Glycerin.) Vergr, 600 (S. Ap. $\frac{1}{15}$, Oc. comp. 4).

Fig. 4. Endothelzelle vom Peritonaeum diaphragmaticum des Meerschweinchens, peripherischer Theil. - Zellen mit langen Fortsätzen. (Salpetersaures Silber.) Vergr. 560 (Obj. $7 *$, Oc. comp. 8).

Fig. 5. Endothel vom Centrum tendineum des Kaninchens. - Fehlen von Oeffnungen zwischen den Zellen. (Salpeters. Silber), Vergr. 560 (Obj. $7 *$, Oc. comp. 8). 
Fig. 6. Endothel vom Peritonaeum diaphragmaticum eines gesunden Bundes. - Hohlraum, zwischen dem Protoplasma dreier benachbarter Zellen, von den oberflächlichen Lamellen überdeckt. Vergr. 1250 (S. Ap. $\frac{1}{15}$, Oc. comp. 8).

Fig. 7. Endothel vom Peritonaeum diaphragmaticum eines gesunden Hundes. - Leukocyten 2 wischen den Endothelzellen. Vergr. 275 (Obj. 7*, Oc. comp. 4).

Fig. 8A. Peritonaeum diaphragmaticum vom Menschen, natürliche Grösse. a Peritonäalbekleidung der Muskelschicht, deren Zona peritendinea mit $\mathrm{Z}$ p bezeichnet ist. b Peritonäum des Centrum tendineum. Zahlreiche Lücken in der Zona peritendinea mit Ausnabme der Peritonäaldecke des grossen Gefässes v.

Fig. 8B. Theil der Zona peritendinea, 3 mal vergrössert. Weite Lücken, die durch Bündel des Stratum reticulare in verschiedene Abtheilungen zerlegt werden (nach Bizzozero und Salvioli).

Fig. 9. Membrana limitans vom Peritonaeum diaphragmaticum peritendineum. - Verschiedene durchlöcherte Zonen, welche ebenso vielen Lücken entsprechen. Vergr. 350 (nach Bizzozero und Salvioli).

Fig. 10. Stück vom Peritonäum der Zona peritendinea. aa kleine Lymphspalten. b b Bündel der netzförmigen Schicht, welche dieselben rings umgeben. ccc Bindegewebsbündel der Stützgewebsschicht d, welche zurn Theil über die Lymphspalte hinwegziehen. e Stück der Grenzmembran, im Gebiet der Spalten vie]fach durchlöchert. Der Rest der Membrana limitans wurde bei der Präparation zufällig entfernt. Vergr. 50 (nach Bizzozero und Salvioli).

Fig. 11. Grenzmembran vom Peritonaeum diaphragmaticum des Menschen. - Zarte Leisten begrenzen flache Nischen, in welchen zum 'Theil noch Endotbelzellen eingebettet liegen. Vergr. 600 (S. Ap. ${ }_{15}^{1}$, Oc. comp. 4).

Fig. 12. Leukocyten, mit kleinen und mittelgrossen Stärkekörnchen beladen. Vergr. 560 (Obj. $7 *$, Oc. comp. 8).

Fig. 13. Grosse, von mebreren Leukocyten umschlossene Stärkekörnchen. Bei $b$ enthalten die Leukocyten noch andere kleine Körnchen. Vergr. 560 (Obj. $7^{*}$, Oc. comp. 8).

Fig. 14. Endothel vom Peritonaeum diaphragmaticum des Hundes während der Aufnahme von. Stärkekörnchen. - Oeffnungen zwischen den Endothelzellen, feine Fortsätze und Protoplasmabrücken. Vergr. 1250 (S. Ap. $\frac{1}{15}$, Oc. comp. 8).

Fig. 15. Andere Stelle desselben Präparates. Leukocyten und Stärkekörnchen im Begriffe, die Endothelschicht zu durchwandern. Vergr. 350 (Obj. $7 *$, Oc. 3). 